\title{
ANÁLISE DA PULVERIZAÇÃO DE UM FUNGICIDA NA CULTURA DO FEIJÃO, EM FUNÇÃO DO TIPO DE PONTA E DO VOLUME APLICADO ${ }^{(1)}$
}

\author{
LUIZ CLAUDIO GARCIA(2); ALTAIR JUSTINO(3); HAMILTON HUMBERTO RAMOS(4)
}

\begin{abstract}
RESUMO
A cultura do feijão (Phaseolus vulgaris L.) é uma das mais importantes na agricultura brasileira. A ocorrência de doenças é um sério fator de influência no seu desenvolvimento e produtividade. Objetivou-se com o experimento instalado no município de Ponta Grossa (PR) analisar diferentes condições de pulverização para aplicação de um fungicida. Semeou-se a cultivar carioca FTBonito em janeiro de 2001. Realizou-se a pulverização do ingrediente ativo azoxystrobin com pulverizador costal pressurizado com $\mathrm{CO}_{2}$. Os tratamentos foram compostos por dois tipos de pontas (jato plano e cônico vazio) e por dois métodos de determinação do volume de calda aplicado, fornecido pelo fabricante e pelo índice de área foliar - IAF. O volume definido pelo IAF foi acurado pela proporcionalidade com o máximo valor do referido índice, obtido previamente por meio de ensaio em estufa. Avaliaram-se a incidência e severidade das doenças e a produtividade. O delineamento experimental adotado foi o de blocos casualizados e as médias obtidas, comparadas pelo teste de Tukey e os grupos de médias, pelo teste de Scheffé. Os dados obtidos demonstraram que foi necessário o tratamento fúngico para a região dos Campos Gerais, na safra das secas, principalmente para o controle de mancha-angular (Phaeoisariopsis griseola). Verificou-se que o tipo de ponta utilizado foi indiferente em relação ao controle quando se aplicou azoxystrobin. $\mathrm{O}$ volume de calda pulverizado pode ser calculado com base no IAF da cultura, com economia até de $69 \%$ do custo de aplicação, nas condições do ensaio.
\end{abstract}

Palavras-chave: área foliar, severidade, produtividade.

\section{ABSTRACT \\ ANALYSIS OF NOZZLE TYPE AND SPRAYING VOLUME \\ OF A FUNGICIDE APPLIED ON THE BEAN CROPS}

Bean (Phaseolus vulgaris L.) is one of the most important crop in Brazilian agriculture. Fungi diseases are among the most restraining production factor. A test was performed aiming to analyze the spraying effect of fungicide based on nozzle type and application volume of a fungicide. The variety carioca FT-Bonito was planted in January/2001 on an experimental plot in Ponta Grossa, State of Paraná. The active ingredient azoxystrobin was sprayed using a pressurized costal spray with $\mathrm{CO}_{2}$. The treatments were composed by two types of nozzles (fan and empty cone) and by two methods of volume determination (manufacturer's recommendation and Leaf Area Index - LAI). The volume for the LAI method was defined by the proportionality with the maximum value of the related index, previously obtained in a greenhouse. The incidence productivity and disease severity were evaluated. The experimental design was plots with random blocks. The average values were compared by Tukey test while group of average values were compared by Scheffé test. The data showed that the treatment with fungicide was necessary for the Campos Gerais area, in the drought season harvest, mainly for the control of the angular leaf spot disease caused by Phaeoisariopsis griseola. Different nozzle types showed no differences when using azoxystrobin. The volume sprayed could be calculated on the culture LAI basis, with economy of up to $69 \%$ of the application cost, in the test conditions.

Key words: leaf area, severity, productivity.

(1) Experimento financiado por bolsa da Universidade Estadual de Ponta Grossa (PIBIC/UEPG/CNPq). Recebido para publicação em 28 de novembro de 2001 e aceito em 29 de agosto de 2002.

$\left(^{2}\right)$ Acadêmico de Agronomia. Universidade Estadual de Ponta Grossa (UEPG), Rua Paulo Pinheiro Schimdt, 366, Uvaranas, 84031-520 Ponta Grossa (PR). E-mail: luizclaudiogarcia@bol.com.br

$\left({ }^{3}\right)$ Departamento de Engenharia Agrícola e Ciências do Solo, UEPG.

(4) Centro Avançado de Pesquisa Tecnológica do Agronegócio de Engenharia e Automação, Instituto Agronômico (IAC), Caixa Postal 26, 13201-970 Jundiaí (SP). 


\section{INTRODUÇÃO}

O Brasil produz e consome, em média, 3,25 milhões de toneladas de feijão por ano, número que coloca o país em segundo lugar no ranking mundial de produtores e consumidores; dentro da federação, o Estado do Paraná apresenta o maior volume de produção (EMBRAPA, 2000).

Atualmente, cerca de 60 doenças atacam a cultura do feijão, sendo 31 causadas por fungos, das quais as tradicionalmente importantes na região dos Campos Gerais sãoa antracnose (Colletotrichumlindemuthianum), ferrugem (Uromyces appendiculatus) e mancha-angular (Phaeoisariopsis griseola), podendo-se empregar a aplicação de fungicidas específicos como componente da estratégia de controle dessas doenças (Dalla-Pria et al., 1999).

Considerando uma pulverização sobre a superfície da cultura, com indicação da quantidade do produto por hectare (dose), em lavoura nova, para um hectare do terreno poderá haver menos de um hectare de folhas, mas em pouco tempo esse hectare de terreno poderá ter várias vezes a área em hectares de superfície vegetal, e, evidentemente, não se deve indicar o mesmo volume de calda para situações tão diferentes. Em geral, a indicação da dose por hectare não vem acompanhada de referência quanto ao tamanho das plantas, no qual reside uma forma de desajuste, normalmente acentuado em plantas pequenas, que pode representar uma sobredosagem apreciável (MATUO, 1990).

A escolha da ponta de pulverização está condicionada ao alvo que se deseja atingir. RAMOS et al. (1998) concluíram que, para jatos plano e cônico em alturas de 0,$15 ; 0,30$ e $0,45 \mathrm{~m}$ do alvo, quando o objetivo da pulverização é atingir um alvo horizontal ou a parte superior de um alvo inclinado, o tipo de jato é indiferente, sendo viável a seleção da ponta em virtude de outras variáveis da pulverização, como por exemplo, o vento. Para alvos verticais, quando o objetivo é apenas a parte frontal, situação que poderia ocorrer na aplicação de produtos sistêmicos, a forma do jato não tende a influir na deposição. No entanto, quando o objetivo é a deposição em ambas as faces, pode-se obter melhores resultados utilizando-se ponta com jato do tipo cônico ou plano duplo.

Buscando testar as recomendações dos autores citados, o experimento teve como objetivo avaliar a pulverização de um fungicida sistêmico preventivo para o controle de antracnose, ferrugem e manchaangular na cultura do feijão, em função do tipo de ponta e do volume de calda utilizado, levando-se em consideração a produtividade e os custos da aplicação.

\section{MATERIAL E MÉTODOS}

Realizou-se a semeadura da cultivar carioca FTBonito, para o ensaio de determinação da área foliar, em vasos de 5 litros, protegidos por estufa de nãotecido, contendo substrato Plant Max ${ }^{\circledR}$, em 15 de dezembro de 2000. O índice de área foliar (IAF), em todos os estádios de desenvolvimento da cultura, foi medido pela fórmula proposta por IAMAUTI (1995): $\mathrm{A}=2,1 \times(\mathrm{L})^{2}$, em que A é a área foliar $\left(\mathrm{cm}^{2}\right)$ e $\mathrm{L}$, a largura máxima do folíolo central do trifólio $(\mathrm{cm})$.

O experimento em campo foi instalado na Fazenda-Escola Capão da Onça, município de Ponta Grossa (PR), altitude de $900 \mathrm{~m}, 25^{\circ} 16^{\prime}$ de latitude Sul e 50 $16^{\prime}$ de longitude Oeste, clima $\mathrm{Cfb}$, em parcelas de $3 \times 7 \mathrm{~m}$, relevo plano, Argissolo VermelhoAmarelo Alumínico alissólico, em sistema de plantio direto sob a palha. Utilizando uma semeadora Semeato modelo PS6, realizou-se a semeadura em 30 de janeiro de 2001, empregando-se o mesmo lote de sementes dos vasos em estufa, com espaçamento de $0,45 \mathrm{~m}$ entre linhas e $0,08 \mathrm{~m}$ entre plantas. As plântulas emergiram em 4 de fevereiro do mesmo ano. Demais atividades de manejo (adubações, controle de plantas daninhas e pragas) foram conduzidas similarmente em todas parcelas, conforme os procedimentos normais recomendados para essa cultura e adotados pela fazenda-escola.

Os tratamentos foram constituídos por quatro aplicações (JA-1 com calda determinada pelo IAF; JA-2 com calda de 200 L.ha $^{-1}$; 110-UF-01 com calda determinada pelo índice de área foliar - IAF e 110UF-02 com calda de 200 L.ha $^{-1}$ ) e pela testemunha (sem tratamento fúngico). Os filtros para bicos utilizados foram de malha 80 para as pontas JA-1 e 110-UF-01 e malha 50 para as pontas JA-2 e 110-UF02, conforme recomendações do fabricante (JАСТO, 2001). Pontas da série UF são do tipo jato plano com fabricação em Kematal ${ }^{\circledR}$ e as pontas da série JA são do tipo jato cônico vazio com fabricação em cerâmica.

As aplicações foram realizadas com pulverizador costal pressurizado com $\mathrm{CO}_{2}$, barra munida de quatro bicos, espaçados em $0,5 \mathrm{~m}$ entre si, pressão de 211 $\mathrm{KPa}$, utilizando o ingrediente ativo azoxystrobin, fungicida sistêmico preventivo, para o controle de antracnose (Colletotrichum lindemuthianum), ferrugem (Uromyces appendiculatus) e manchaangular (Phaeoisariopsis griseola). Antes de cada pulverização, mediu-se o IAF pelo mesmo método empregado nas plantas em estufa, definindo o volume da calda pela proporção entre o valor encontrado e o índice máximo obtido na mesma cultivar em cultivo protegido, considerando-se 200 
L.ha ${ }^{-1}$ como o volume a ser aplicado na situação de IAF máximo. Os diferentes volumes de calda foram obtidos pela variação na velocidade de aplicação.

Os efeitos do tratamento fungicida, das pontas e do volume da calda pulverizado sobre a cultura foram avaliados aos 72 dias após a emergência pela coleta, ao acaso, de 30 folhas de cada parcela (10 na parte superior, 10 na parte mediana e 10 na parte inferior das plantas). Mediu-se a incidência das doenças, utilizando-se as escalas diagramáticas de severidade, apresentadas em DALLA-PRIA et al. (1999).

Também se mensurou a produtividade, colhendose a cultura aos 87 dias após a emergência, com quatro repetições de $1 \mathrm{~m}^{2}$, escolhidas aleatoriamente, totalizando $4 \mathrm{~m}^{2}$ por parcela. Retirou-se a umidade e as impurezas, pesou-se e converteu-se a referida produção em kg.ha-1.

O delineamento experimental foi o de blocos casualizados, com 4 repetições. Analisou-se a homocedasticidade pelo teste de Hartley; posteriormente, aplicou-se o teste F. A comparação múltipla de médias foi realizada pelo teste de Tukey. Para a verificação dos contrastes que envolvem grupos de médias, utilizou-se o teste de Scheffé, conforme indicações de BANZATTO e KRONKA (1995).

O cálculo da diferença do custo da pulverização, entre os métodos de determinação do volume de calda fornecido pelo fabricante e IAF, teve como base os dados da FundAÇÃo ABC (2001), levando-se em conta mão-de-obra, trator de $52,2-66,2 \mathrm{~kW} / 4 \mathrm{R}$, pulverizador com tanque de $200 \mathrm{~L}$ e barra de $14 \mathrm{~m}$.

\section{RESULTADOS E DISCUSSÃO}

Obteve-se o ponto máximo do IAF, em condições de estufa, aos 60 dias após a emergência, no estádio de antese plena. O IAF máximo foi 8 , significando haver oito vezes mais superfície de folhas do que superfície de solo. Quando da instalação da cultura no campo, o IAF máximo foi de 2,5, aos 40 dias após a emergência. Tal fato ocorreu pelo alto grau de incidência e severidade da doença denominada mancha-angular, que entre os sintomas apresenta desfolhamento precoce (Figura 1).

Com a medição do IAF antes de cada pulverização, chegou-se aos volumes de calda pulverizada pelo estádio de desenvolvimento da cultura (Quadro 1). Alerta-se que em condições de campo, as pontas JA-1 e 110-UF-01, por necessitarem de peneira malha 80 para o bico, podem não representar soluções viáveis, principalmente para as formulações pó molhável (PM) e suspensão concentrada (SC).

Historicamente, a ocorrência da mancha-angular já é comum na safra da seca na região dos Campos Gerais (PR), mesmo com controle químico preventivo. O ano agrícola 2000/01 apresentou, porém, condições climáticas ideais para proliferação do agente etiológico Phaeoisariopsis griseola, com temperaturas entre $18^{\circ} \mathrm{C}$ e $25^{\circ} \mathrm{C}$, períodos de alta umidade para infecção e desenvolvimento e intervalos com baixa umidade para disseminação de esporos (Figura 2). Em relação às doenças ferrugem
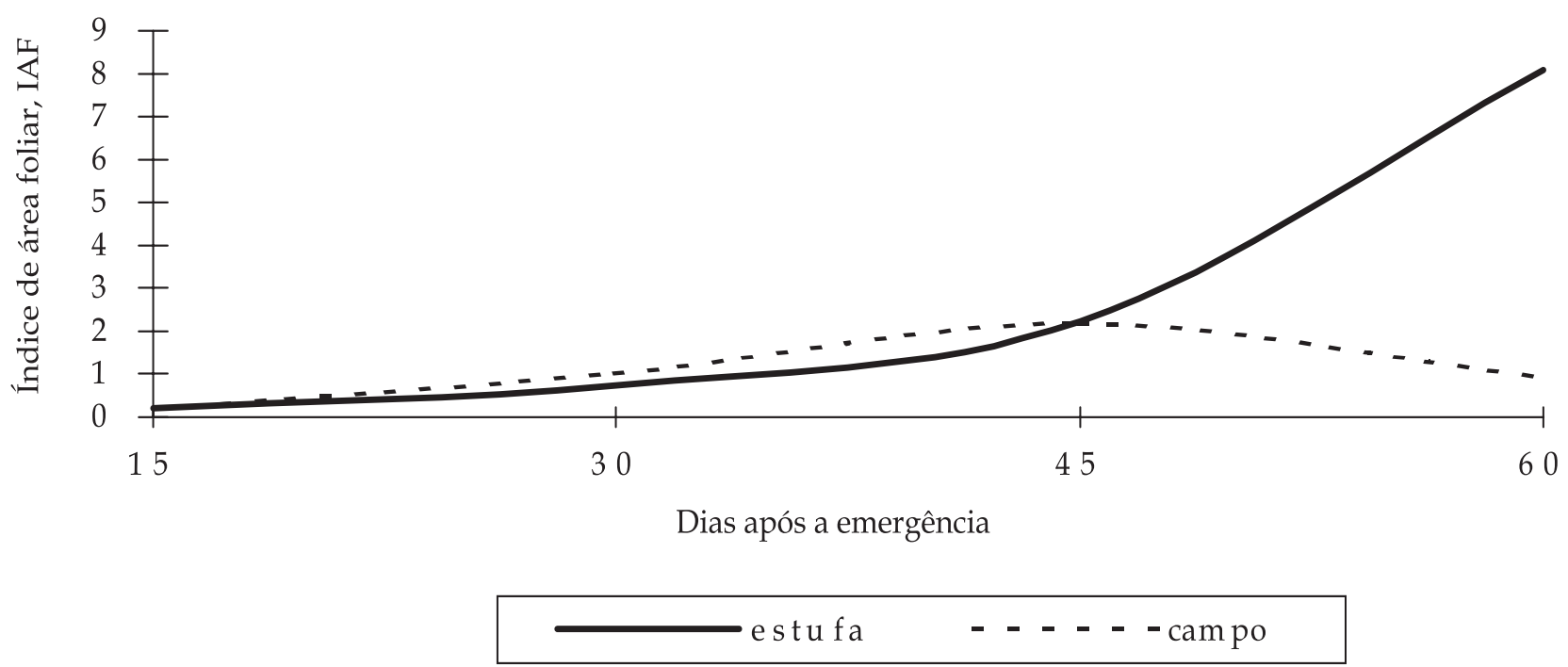

Figura 1. Índice da área foliar (IAF), durante o ciclo da cultivar de feijão FT-Bonito, safra da seca, plantada em estufa e campo. Ponta Grossa (PR), 2001. 
Quadro 1. Pulverização de azoxystrobin, com equipamento costal pressurizado por CO, sobre a cultivar de feijão FTBonito, na safra da seca, utilizando-se pontas do tipo jato cônico vazio e jato plano e com volume de calda indicada pelo fabricante do produto e determinada pelo índice de área foliar

\begin{tabular}{|c|c|c|c|c|}
\hline $\begin{array}{c}\text { Data da } \\
\text { pulverização }\end{array}$ & $\begin{array}{l}\text { Dias após a } \\
\text { emergência }\end{array}$ & Pontas & Filtro do bico & Volume da calda \\
\hline \multirow{4}{*}{$19 / 2 / 2001$} & \multirow{4}{*}{15} & JA-1 jato cônico vazio & Malha 80 & 60 L.ha $^{-1}$ (determinado pelo IAF) \\
\hline & & JA-2 jato cônico vazio & Malha 50 & 200 L.ha $^{-1}$ (indicado pelo fabricante) \\
\hline & & 110-UF-01 jato plano & Malha 80 & 60 L.ha $^{-1}$ (determinado pelo IAF) \\
\hline & & 110-UF-02 jato plano & Malha 50 & 200 L.ha $^{-1}$ (indicado pelo fabricante) \\
\hline \multirow{4}{*}{$06 / 3 / 2001$} & \multirow{4}{*}{30} & JA-1 jato cônico vazio & Malha 80 & 90 L.ha $^{-1}$ (determinado pelo IAF) \\
\hline & & JA-2 jato cônico vazio & Malha 50 & 200 L.ha $^{-1}$ (indicado pelo fabricante) \\
\hline & & 110-UF-01 jato plano & Malha 80 & 90 L.ha $^{-1}$ (determinado pelo IAF) \\
\hline & & 110-UF-02 jato plano & Malha 50 & 200 L.ha $^{-1}$ (indicado pelo fabricante) \\
\hline \multirow{4}{*}{$21 / 3 / 2001$} & \multirow{4}{*}{45} & JA-1 jato cônico vazio & Malha 80 & 135 L.ha $^{-1}$ (determinado pelo IAF) \\
\hline & & JA-2 jato cônico vazio & Malha 50 & 200 L.ha $^{-1}$ (indicado pelo fabricante) \\
\hline & & 110-UF-01 jato plano & Malha 80 & 135 L.ha $^{-1}$ (determinado pelo IAF) \\
\hline & & 110-UF-02 jato plano & Malha 50 & 200 L.ha $^{-1}$ (indicado pelo fabricante) \\
\hline
\end{tabular}

Testemunha

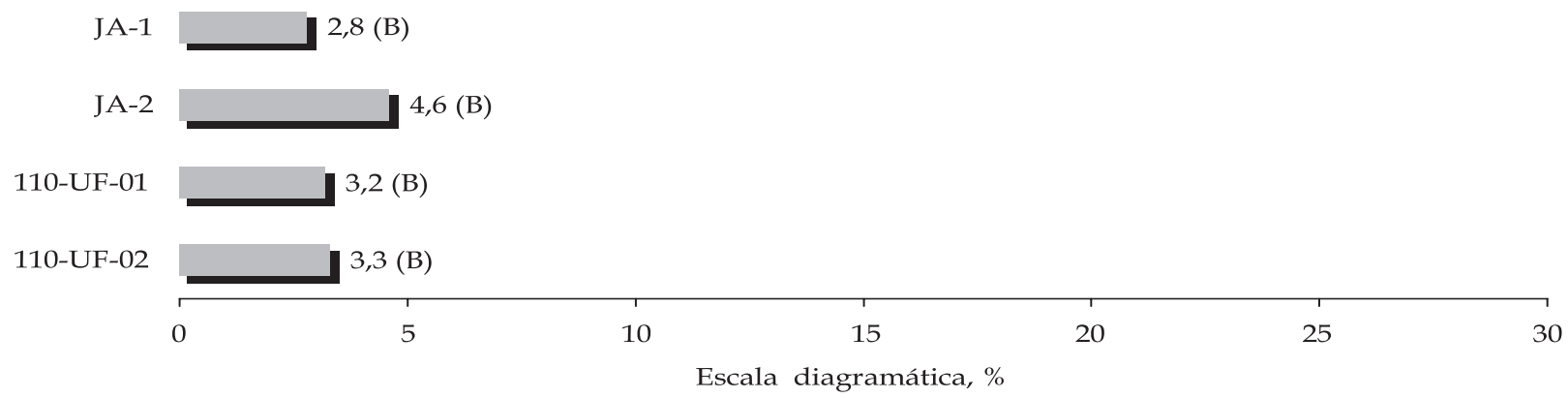

Figura 2. Severidade de mancha-angular na cultivar de feijão FT-Bonito, na safra da seca, para tratamento fúngico com azoxystrobin, utilizando-se pontas do tipo jato cônico vazio e plano e com volume de calda indicada pelo fabricante do produto e determinada pelo índice de área foliar. Médias seguidas por diferentes letras maiúsculas diferem, entre si, pelo teste de Tukey ao nível de $1 \%$ de probabilidade. A diferença foi significativa para aos blocos, pelo teste de Tukey ao nível de 5\% de probabilidade. DMS (Tukey) igual a 4,54 e CV correspondente a 24,02\%.

Testemunha 988 (A)

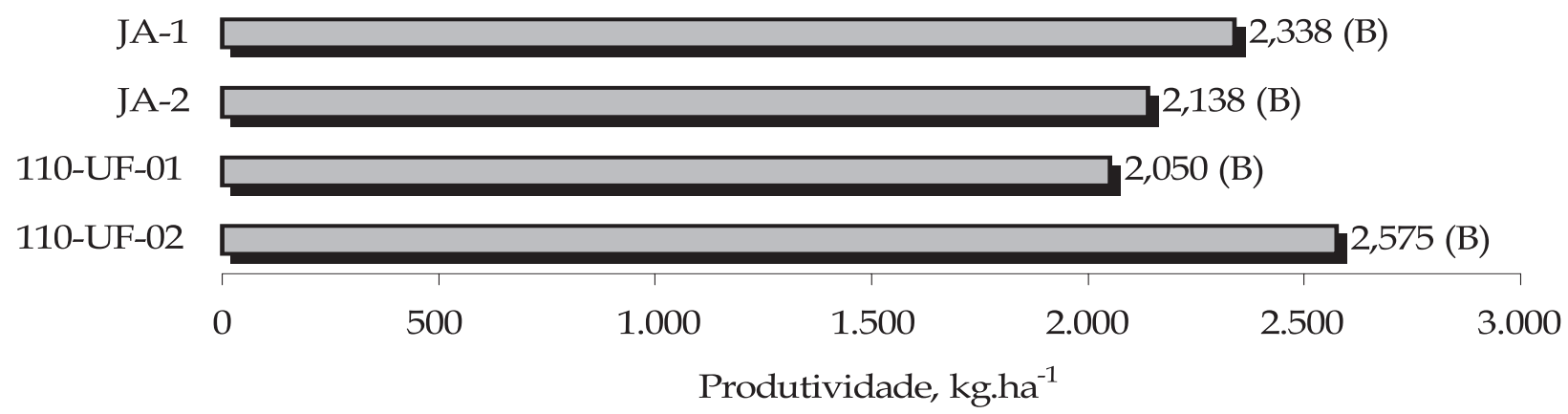

Figura 3. Produtividade da cultivar de feijão FT-Bonito, na safra da seca, para tratamento fúngico com azoxystrobin, utilizando-se pontas do tipo jato cônico vazio e plano e com volume de calda indicada pelo fabricante do produto e determinada pelo índice de área foliar. Médias seguidas por diferentes letras maiúsculas diferem, entre si, pelo teste de Tukey ao nível de $1 \%$. A diferença foi significativa para os blocos, pelo teste de Tukey ao nível de $5 \%$. DMS (Tukey) igual a 704,05 e CV correspondente a 15,48\%. 
e antracnose, não se constataram incidência e severidade significativa de ambas na cultura, o que também é freqüente para este período na região.

Verifica-se que houve diferença estatística significativa na produtividade da cultura do feijão entre a testemunha e os tratamentos, com grau de confiança superior a $99 \%$ de probabilidade. Já entre os tratamentos, não se observou diferença significativa no que se refere à produtividade (Figura 3 ).

Ao aplicar o teste de Scheffé para testar os possíveis contrastes entre os grupos de médias que envolviam aplicação com ponta tipo jato plano versus cônico vazio, concluiu-se pela não- significância com grau de confiança superior a $95 \%$ de probabilidade. Ao testar as médias de produtividade obtidas por pulverização com volume de calda de 200 L.ha $^{-1} \mathrm{em}$ contraste com o volume definido pelo IAF, verificouse diferença não significativa ao nível de $5 \%$.

Considerando o custo da pulverização, que segundo a FUNDAÇÃo AвC (2001) era de R\$30,44 por hora, em abril de 2001, observa-se que, nas condições do ensaio, os custos com a aplicação seriam reduzidos de $\mathrm{R} \$ 5,44$ por hectare para o volume de 200 L.ha $^{-1}$ para $\mathrm{R} \$ 3,62 ; \mathrm{R} \$ 2,42$ e $\mathrm{R} \$ 1,67$ por hectare, respectivamente, para os volume de 135, 90 e 60 L.ha $^{-1}$. Dessa forma, pode-se obter redução até de $69 \%$ nos custos com a aplicação pela adequação do volume por meio da área foliar, sem que isso resulte em perda de eficiência do fungicida azoxystrobin.

\section{CONCLUSÕES}

1. O tratamento fúngico, na safra da seca, foi necessário para a cultura do feijão na região dos Campos Gerais (PR), principalmente para mancha-angular.

2. Para o tratamento de doenças fúngicas, com azoxystrobin nas condições do ensaio, o tipo de ponta escolhida, jato cônico vazio ou plano foi indiferente.
3. A severidade da mancha-angular e a produtividade da cultura não foram influenciadas pelo método de determinação do volume da calda, entretanto, o da calda pulverizada, calculada com base no IAF, reduz até $69 \%$ o custo da aplicação.

\section{REFERÊNCIAS BIBLIOGRÁFICAS}

BANZATTO, D.A.; KRONKA, S.N. Experimentação Agrícola. 3.ed. Jaboticabal: FUNEP, 1995. 247p.

DALLA-PRIA, M.; SILVA, O.C. da; COSTA, J.L. da S.; SOUZA, E.D. de T.; BERNI, R.F. Métodos de avaliação das doenças. In: CANTERI, M.G. Principais doenças fúngicas do feijoeiro. Ponta Grossa: Editora UEPG, 1999. p.17-25.

EMBRAPA. Feijão. Disponível em: http:// www.embrapa.com.br. Acesso em: 5 de março de 2001.

FUNDAÇÃO ABC. Custo de mecanização agrícola. Castro: Fundação $A B C$, 2001. ano 3, n.14, p.33.

IAMAUTI, M.T. Avaliação de danos causados por Uromyces appendiculatus no feijoeiro. 1995. 93f. Tese (Doutorado em Agronomia) - Escola Superior de Agricultura "Luiz de Queiroz", Universidade de São Paulo, Piracicaba.

JACTO. Produtos. On-line. Disponível em: http:// www.jacto.com.br. Acesso em: 5 de janeiro de 2001.

MATUO, T. Técnicas de aplicação de defensivos agrícolas. Jaboticabal: FUNEP, 1990, p.3-86.

RAMOS, H.H.; MATUO, T.; ALMEIDA, A.N. et al. Cobertura do alvo pela pulverização com bico hidráulico em função do tipo de jato, posição do alvo e altura de aplicação. In: CONGRESSO BRASILEIRO DE ENGENHARIA AGRÍCOLA, 27., 1998, Poços de Caldas. Anais... Lavras: UFLA/SBEA, 1998. v.3, p.169-171. 